\title{
Terapotik Hipotermide Nörogelişimsel Sonuçlar: Tek Merkez Deneyimi
}

\author{
Neurodevelopmental Outcomes in Therapeutic Hypothermia: A \\ Single Center Experience
}

Kıymet ÇELIK' ${ }^{1}$, Zeynep ÜSTÜNYURT² ${ }^{2}$ Ezgi YANGIN ERGON³ , Rüya ÇOLAK ${ }^{5}$, Senem ALKAN ÖZDEMIR², Özgür OLUKMAN ${ }^{4}$, Şebnem ÇALKAVUR ${ }^{5}$

\author{
${ }^{1}$ Akdeniz Üniversitesi Tıp Fakültesi, Çocuk Sağlı̆ı ve Hastalıkları Anabilim Dalı, Yenidoğan Bilim Dalı, Antalya, Türkiye \\ ${ }^{2}$ Behçet Uz Çocuk Hastalıkları ve Cerrahisi Eğitim Araştırma Hastanesi, Gelişimsel Pediatri Bölümü, İmir, Türkiye \\ ${ }^{3}$ Manisa Șehir Hastanesi, Yenidoğan Bölümü, Manisa, Türkiye \\ ${ }^{4}$ Çiğli Bölge Eğitim Hastanesi, Yenidoğan Bölümü, Manisa, Türkiye \\ ${ }^{5}$ Behçet Uz Çocuk Hastalıkları ve Cerrahisi Eğitim Araștırma Hastanesi, Yenidoğan Kliniği, İmir, Türkiye
}

\section{Öz}

Amaç: Hipoksik iskemik ensefalopati (HiE), perinatal asfiksi sonucunda gelişen akut ve ilerleyici bir ensefalopati tablosudur. Genellikle HiE tanılı hastaların \%15'i kaybedilirken, yaklaşı \%25'inde nörolojik bozukluk görülmektedir. Bu çalışmada HíE tanılı hastalarda total vücut soğutma tedavisinin 18-36. aylarındaki nörogelişimsel sonuçlar üzerine etkilerinin değerlendirilmesi amaçlanmıştır.

Gereç ve Yöntemler: Çalışmaya 2013-2014 yıllarında, HíE tanısı ile yatırılarak total vücut soğutma uygulanan hastalar dahil edildi. Taburculuk sonrası izlemlerine devam edilen bu hastaların 18-36 ay arasında nörolojik muayeneleri ve "Bayley Bebekler için Gelişimsel Değerlendirme Ölçeği II” ile gelişimsel değerlendirmeleri yapıldı.

Bulgular: Çalışmaya alınan 17 hastanın ortalama mental gelişim endeksi (MDI) skoru 90.2 \pm 16.3 , ortalama psikomotor gelişim endeksi (PDI) skoru 93.8 \pm 17.3 , MDI skoru \%11.8 (n:2) olguda <70, PDI skoru \%5.9 (n:1) olguda <70, sağılık ve serebral palsi \%5.9 (n:1) olguda saptanmış olup, körlük hiçbir hastada saptanmadı. Toplam nörogelişimsel sorun oranı ise \%17.6 (n:3) olarak saptandı.

Sonuç: HíE’li yenidoğanlarda hipotermi uygulamasıyla beraber orta ve ağır HíE'li olgularda mortalitenin azaldığı ve 18. ayda nörogelişimsel sonuçları olumlu etkilediği gösterilmiştir. Çalışmamızda da terapotik hipotermi sonrası erken dönem nörolojik ve gelişimsel sorun oranları literatür ile benzer bulunmuştur. Ancak bu hastalarda minör bozuklukların saptanması için izlemlerin devamı gerekmektedir.

Anahtar Sözcükler: Hipoksik iskemik ensefalopati, Hipotermi, Yenidoğan

\section{ABSTRACT}

Objective: Hypoxic-ischemic encephalopathy $(\mathrm{HIE})$ is an acute and progressive encephalopathy resulting from perinatal asphyxia. Approximately 15\% infants with neonatal HIE die, whereas 25\% exhibit subsequent neurological disabilities. In this study, it was intended to compare effects of total body cooling treatment administered for hypoxic-ischemic encephalopathy on neurological and developmental findings obtained at 18-36 months.

\section{(i)}

ÇELIKK

ÜSTÜNYURT Z

YANGIN ERGON E

ÇOLAKR

ALKAN ÖZDEMIR S

OLUKMAN Ö

ÇALKAVUR Ş
Çıkar Çatışması / Conflict of Interest: Tüm yazarlar adına, sorumlu yazar çıkar çatıșması olmadığını belirtir.

: 0000-0002-4522-6885 : 0000-0001-8297-2097 : 0000-0003-0836-7379 : 0000-0002-8732-7932 : $0000-0003-4006-0465$ :0000-0002-3820-2690

Etik Kurul Onayı / Ethics Committee Approval: Bu çalıșmada ulusal ve uluslararası etik kurallara uyulmuştur. Behçet Uz Çocuk Hastalıkları ve Cerrahisi Eğitim Araştırma Hastanesi, Klinik Araşıırmalar Ețik Kurulu etik kurul onayı alındı (2016/89). Kayıt sırasında veliler tarafından araştırmaya katılım çin bilgilendirilmiş bir onay imzalanmıștır.

Yazarların katkısı / Contribution of the Authors: ÇELiK K: Araștırma ve/veya makalenin hipotezini veya fikrini oluşturan, Sonuçlara ulașmak için planlama/metodoloji belirleme, Hasta takibinde sorumluluk almak, ilgili biyolojik malzemelerin toplanması, veri yönetimi ve raporlama, deneylerin yürütülmesi, ÜSTÜNYURT Z: Araştırma ve/veya makalenin hipotezini veya fikrini oluşturan, Sonuçlara ulaşmak için planlama/metodoloji belirleme, Araştırma/çalıșmanın sorumluluğunu üstlenmek, ilerlemenin seyrini denetlemek, Çalışmanın bütününün veya önemli bölümlerinin yazımında sorumluluk almak. YANGIN ERGON E: Hasta takibinde sorumluluk almak, ilgili biyolojik malzemelerin toplanması, veri yönetimi ve raporlama, deneylerin yürütülmesi, Çalısmanın bütününün veya önemli bölümlerinin yazımında sorumluluk almak. COLAK R: Hasta takibinde sorumluluk almak, ilgili biyolojik malzemelerin toplanmas, veri yönetimi ve raporlama, deneylerin vürütülmesi, Calșmanın bütününün veya önemli bölümlerinin yazımında sorumluluk almak $\mathbf{A L K A N}$ toplanmas, , Ö: Hasta takibinde sorumluluk almak, ilgili biyolojik malzemelerin toplanması, veri yönetimi ve raporlama, deneylerin yürütülmesi, ÇALKAVUR S: O: Hasta takibinde sorumluluk almak, ilgili biyolojik malzemelerin toplanması, veri yönetimi ve raporlama, deneylerin yürütülmesi, ÇALKAVUR S:
Araștırma/çalıșmanın sorumluluğunu üstlenmek, ilerlemenin seyrini denetlemek, yazım ve dilbilgisi dıșında bilimsel olarak gönderilmeden önce makaleyi gözden geçirme.

Atıf yazım șekli / How to cite : Çelik K, Üstünyurt Z, Yangın Ergon E, Çolak R, Alkan Özdemir S, Olukman Ö ve ark. Terapotik Hipotermide Nörogelișimsel Sonuçlar: Tek Merkez Deneyimi. Türkiye Çocuk Hast Derg 2021;15: 99-103.
Yazışma Adresi / Correspondence Address:

Kıymet ÇELIK

Akdeniz Üniversitesi Tıp Fakültesi, Çocuk Sağlığı ve Hastalıkları Anabilim Dalı,

Yenidoğan Bilim Dall, Antalya, Türkiye

E-posta: kiymetcelikmd@gmail.com
Geliş tarihi / Received : 13.04.2020 Kabul tarihi / Accepted : 10.06.2020 Elektronik yayın tarihi $\quad 29.09 .2020$ Online published

DOI: 10.12956/tchd.719789 
Material and Methods: Patients who have been hospitalized between 2013 and 2014 in Neonatal Intensive Care Unit with a diagnosis of hypoxic-ischemic encephalopathy and treated total body cooling were included. After discharge, neurological examinations of the patients were evaluated by developmental assessments with "Bayley Scales of Infant Development II" at 18-36 months.

Results: Mean MDI score of 17 patients was 90.2 \pm 16.3 , and mean PDI score was 93.8 \pm 17.3 . MDI scores were < 70 in $11.8 \%(n=2)$ of all cases, and PDI scores were $<70$ in $5.9 \%(n=1)$ of all cases. In $5.9 \%(n=1)$ of all cases, deafness and cerebral palsy were detected. Developmental disorder were found in $17.6 \%(n=3)$ of all cases.

Conclusion: The therapeutic hypothermia in newborns decreased mortality in moderate and severe HIE and improved neurodevelopmental outcomes at 18th month. In our study, early neurological and developmental problem rates after therapeutic hypothermia were found similar with the literature. However, long period follow-up is necessary to determine minor disorders in these patients.

Key Words: Hypoxic-Ischemic Encephalopathy, Hypothermia, Newborn

\section{GiRiş}

Hipoksik iskemik ensefalopati (HiE), perinatal asfiksi sonucunda gelişen akut ve ilerleyici bir ensefalopati tablosudur. Gelişmiş üklelerde gelişmiş ülkelerde her 1000 canlı doğumda 0.51 oranında görülür (1). Türkiye'de, Türk Neonatoloji Derneği Hipoksik İskemik Ensefalopati Çalışma Grubu'nun verilerine göre, sıklık binde 2,6, yenidoğan yoğun bakım ünitelerinde yatan hastalar içinde \%1.2 olarak saptanmıştır (2). HiE ilişkili mortalite yenidoğan yoğun bakımındaki tüm gelişmelere karşın yüksektir, yaşayan yenidoğanların ise \%25'inden fazlasında serebral palsi (CP), gelişimsel ve bilişsel alanda gecikme/gerilik görülmektedir (3). Hipksik iskemik bir durum kaynaklı serebral hasarın derecesi temel olarak nöronal nekroz, enflamasyon ile endojen koruma (akut faz yanıtı, iyileşme ve nöronal onarım gibi) arasındaki dengeye bağlıdır. Günümüzde HIE'nin tedavisinde nöroprotektif etkisi nedeniyle yer edinmiş olan hipotermi tedavisi uygulanmaktadır.Terapötik hipoterminin nöroprotektif etkisi, enflamatuar kaskadın inhibisyonu, reaktif oksijen ürünlerinin üretiminin azalması, düşük oksijen tüketimi ve karbon dioksit üretimi ile metabolik hızın azaltıması ve endojen nöroprotektif etki gibi mekanizmaların modülasyonunu içerir (4-7). Yapılan çalışmalarda hafif derecede 72 saat uygulanan hipoterminin orta ve ağır HíE'li olgularda mortaliteyi azalttığı, 18. ayda yapılan değerlendirmelerde nörolojik ve gelişimsel alanda olumlu sonuçları olduğu gösterilmiştir. Hipotermi etkilerinin 6-7 yaşta da devamı konusunda yapılan çalışmalarda ölüm ve $\mathrm{IQ}<70$ oranının hipotermi uygulanan hastalarda daha düşük oranda olduğu gösterilmiştir (8-12). Hipotermi tedavisinin olumlu sonuçları nedeniyle hafif HIE'li olgulara bile uygulanması gündeme gelmiştir. Ancak hafif HiE'li olgularda hipoterminin önerilmesi için hala yeterli kanıt bulunmamaktadır(13,14).

Taburcu edilen HIE tanılı bebeklerin erken dönem takiplerinde Bayley II ve son zamanlarda özellikle Bayley III motor ve psikososyal gelişimsel değerlendirme indeksleri kullanılmaktadır.

Bu çalışmada hipoksik iskemik ensefalopati tablosunda total vücut soğutma tedavisinin erken dönemde nörolojik ve gelişimsel sonuçlar üzerine etkilerinin değerlendirilmesi planlanmıştır.

\section{GEREÇ ve YÖNTEMLER}

Çalışmamıza Dr. Behçet Uz Çocuk Hastalıkları ve Cerrahisi Eğitim Araştırma Hastanesi Yenidoğan Yoğun Bakım Ünitesi'ne, 2013-2014 yılları arasında, hipoksik iskemik ensefalopati tanısı ile yatırılarak total vücut soğutma uygulanan hastalar dahil edildi. Etik kurul onayı alındı (2016/89). HïE tanısı 5. dakika Apgar skorunun 5 ve altında olması, kord kan gazı veya ilk 1 saatte alınan kan gazında metabolik veya miks asidoz varlığı (ph< 7.0, BE<-12), neoanatal ensefalopati varlığı ve multiorgan yetmezliğinin olması ile konuldu. HíE tanısı alan ve klinik olarak orta veya ağır ensefalopati olarak değerlendirilen hastalara total vücut soğutma bașlandı. HİE evrelemesi için Sarnat\&Sarnat değerlendirmesi kullanıldı. Tüm hastalara toplam 72 saat süreyle hafif hipotermi (33-34 $\mathrm{C}^{\circ}$ ) uygulandı. Soğutma işlemi Tecotherm Neo (Inspiration Healthcare, UK) (ASTEK Medikal, Türkiye) cihazı ile uygulandı. Hastaların gestasyonel hafta, doğum ağırlığı, cinsiyet, doğum şekli, hipotermi başlama zamanı (saat), ilk muayenelerindeki Sarnat\&Sarnat evresi, hastane yatış süresi, konvansiyonel EEG sonucu, kraniyal ve difüzyon MR sonucu ile taburculuk fizik muaeyenesi dosyalardan retrospektif inceleme ile kaydedildi. Taburculuk sonrası izlemlerine devam edilen bu hastaların nörolojik muayeneleri ve "Bayley Bebekler için Gelişimsel Değerlendirme Ölçeği II" ile gelişimsel değerlendirmeleri yapıldı. Gelişimsel Pediatrist tarafından aile onamı alınarak, Bayley Bebekler için Gelişimsel Değerlendirme Ölçeği II testi ile değerlendirildi. Bayley II Ölçeği ile Mental Gelişim Endeksi (MDI) ve Psikomotor Gelişim Endeksi (PDI) belirlendi. Serebral palsi; anormal kas tonusu, kalıcı ya da abartılı primitif refleksler ya da hareket alanında gecikme ile ilişkili pozitif Babinski ile karakterize ilerleyici olmayan motor fonksiyon bozukluğu olarak tanımlandı. Nörolojik ve gelişimsel bozukluk (neurodevelopmental impairment) (NDI) aşağıdakilerden en az birinin varlığı ile tanımlandı 1- Orta-ağır serebral palsi (CP), 2- Bilateral işitme kaybı ve/veya körlük, ve 3- MDI veya PDI puanının <70 olması(15). İstatistiksel analiz SPSS for Windows, versiyon 22.0 ile yapıldı. Veriler, frekans, ortalama, ortanca ve standart sapmalar gibi temel istatistikler kullanılarak analiz edildi. 


\section{BULGULAR}

Çalışma döneminde total vücut soğutma uygulanan 21 hastadan ikisinin kaybedilmiş olması, 2 hastaya ulaşılamaması nedeniyle geriye kalan 17 hasta değerlendirmeye alındı. Hastaların \%5.8 (1) Sarnat evre 1, \% 82 (14) evre2, \%12.2 (2) evre 3'dü. Evre 1 olarak değerlendirilen hasta izleminde konvülzyon geçirmesi üzerine hipotermi tedavisi uygulandı. Hastaların \%76 (13)'sına ilk 6 saat içinde hipotermi başlanırken, tamamına ilk 24 saate hipotermi başlandı. Hipoterminin erken sonlandırımasına neden olacak herhangi bir yan etki gözlenmedi. Tüm hastaların hipotermi tedavisi 72 saatlik süreyle uygulandı. Hastaların \%47 (8)'de EEG'de bozukluk (konvülzyon ve/ya da serebral disfonksiyon), \%41 (7)'inde Kraniyal/Difüzyon MR'da patoloji (iskemi/kanama) saptandı. Taburculuk fizik muayenesi patolojik olan hasta oranı \%29 (5) olarak saptandı. Hastaların demografik ve klinik verileri Tablo l'de verilmiştir.

Tablo I: Hastaların demografik ve klinik verileri

\begin{tabular}{lc}
\hline & Ortalama \pm SD \\
\hline Doğum ağırlığı(gram) & $3279 \pm 525$ \\
Doğum haftası & $39 \pm 1.6$ \\
\hline Erkek cinsiyet & $\% 59(10)$ \\
\hline Sezaryen doğum & $\% 11(2)$ \\
Hastane yatış süresi* $^{*}$ & $12(6-54)$ \\
cEEG bulgusu $^{\dagger}$ & $\% 47(8)$ \\
Kraniyal MR bulgusu $^{\ddagger}$ & $\% 41(7)$ \\
\hline Taburculukta patolojik nörolojik muayene & $\% 29(5)$ \\
\hline
\end{tabular}

* Median (minimum-maksimum) olarak verilmiştir, tKonvansiyonel elektroensefalografi, „łKraniyal Manyetik Rezonans görüntüleme

Tablo II: Hastaların nörogelişimsel sonuçları.

\begin{tabular}{l|c|c|c|c}
\multicolumn{1}{c|}{ Değişkenler } & Ortalama \pm SD & En küçük & En büyük & $\%(\mathbf{n})$ \\
\hline Değerlendirme zamanı (ay) & $25.4 \pm 5.8$ & 18 & 34 & - \\
\hline MDI $^{*}$ & $90.2 \pm 16.3$ & 49 & 110 & - \\
\hline PDI $^{\dagger}$ & $93.8 \pm 17.3$ & 49 & 113 & - \\
\hline MDI<70 & - & - & - & $\% 11.8(2)$ \\
\hline PDI<70 & - & - & - & $\% 5.9(1)$ \\
\hline Serebral palsi & - & - & - & $\% 5.9(1)$ \\
\hline Sağırlık & - & - & - & $\% 5.9(1)$ \\
\hline Körlük & - & - & - & - \\
\hline Nörogelişimsel bozukluk & - & - & - & $\% 17.6(3)$ \\
\hline
\end{tabular}

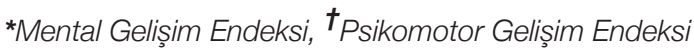

Hastaların ortalama değerlendirme zamanı $25.4 \pm 5.8$ ay olarak saptandı. Değerlendirmeye alınan hastaların ortalama MDI skoru 90.2 \pm 16.3 , ortalama PDI skoru 93.8 \pm 17.3 , MDI skoru \%11.8 (2) olguda <70, PDI skoru \%5.9 (1) olguda $<70$, sağırlık ve serebral palsi \%5.9 (1) olguda saptanmış olup, körlük hiçbir hastada saptanmamıştır. Nörogelişimsel bozukluk ise tüm hastalar değerlendirildiğinde \%17.6 (3) oranında saptanmıştır. Hastane yatış süresi ile MDI ve PDI skoru arasında anlamlı bir ilişki saptanmadı. Nörogelişimsel sonuçlar Tablo Il'de ayrıntıı olarak verilmiştir.

\section{TARTIŞMA}

Bu çalışmada hipopsik iskemik ensefalopati tanılı hastalarda terapotik hipotermi sonrası erken dönem (18-36y) nörolojik ve gelişimsel bozukluk oranı \% 17.6 oranında saptanmıştır. Hastalardan MDI skoru $<70$ olanlar \%11.8, PDI skoru $<70$ olanlar \%5.9, serebral palsi oranı ise \%5.9 saptanmıştır. Hipoksik iskemik ensefalopati, COOLCAP (cooling of head with a cap), $\mathrm{NICHHD}$ (The National Institute of Child Health and Human Development), neo. nEURO ve TOBY (total body hypothermia for neonatal encephalopaty trial) tüm vücut soğutma çalışmalarının erken dönem sonuçları yayınlanıncaya kadar yaklaşı \%60 oranında mortalite ve nörogelişimsel bozukluk ile sonuçlanmaktaydı. Ancak bu çalısmaların sonuçlarına göre hipotermi ile mortalite, gelișimsel ve nörobilișsel bozukluk oranında azalma gözlenmiştir. Hipotermi uygulamasılyla beraber orta ve ağır HiE'li olgularda nörolojik problemler olmadan hayatta kalma oranının, hipotermi uygulanmayan gruba göre daha yüksek olduğu, serebral palsi ile orta ve ciddi engellilik oranının önemli oranda azaldığı gösterilmiştir (8-12). Orta ve ağır 
enselopatide hipotermi uygulanan hastalar ile kontrol grubunun kıyaslandığı TOBY çalışmasında, 18. ayda Bayley Scales Of Infant Development II değerlendirmesinde tedavi grubunda PDI skoru $<70$, MDI skoru $<70$ ve serebral palsi oranları sırasıly $\% 24,24,28$, kontrol grubunda ise $\% 35,34,41$ oranında saptanmıştır. Çalışmanın devamında aynı hasta grubunun 6-7 yaş döneminde yapılan değerlendirmesinde mortalite açısından fark saptanmazken, hipotermi grubunda kontrol grubundan daha fazla çocuk nörolojik anormallik olmadan ve daha iyi motor fonksiyon skorları ile hayatta kalırken, CP ve orta veya şiddetli sakatlık oranları kontrol grubuna göre daha düşüktü (12). COOLCAP çalışmasında 18-22 ayda hipotermi uygulanan hastaların Bayley II değerlendirmesi yapılarak elde edilen veriler ile bu hastaların 7-8 yaş döneminde özbakım, bilişsel ve motor fonksiyonları değerlendiren WeeFIM testi ile elde edilen veriler ile uyumlu olduğu ve hipoterminin uzun dönem olumlu etkilerinin devam ettiği belirtilmiştir. $(16,17)$.

Orta ve ağır HIE tanılı hastalarda hipoterminin faydası net olmakla beraber hafif HiE'li olgularda henüz terapotik hipotermi uygulanmasını önerecek yeterli kanıt bulunmamaktadır $(13,14)$. Ancak Finder M. ve ark'larının (18) yaptığı multisentrik prospektif kontrollü çalışmada hipotermi uygulanmayan hafif HIE'li hastaların bilişsel skorlarının sağlıkı kontrol grubuna göre düşük olduğu, ancak hipotermi uygulanan orta HiE'li hastalar ile de benzer olduğu saptanmıştır. Bu çalsşmanın verileri hafif HIE hastalarına hipotermi uygulaması sorusunu akla getirmekle beraber, orta HiE'li hastalarda da hipoterminin olumlu etkisini göz önüne sermektedir.

Hipoterminin sekonder enerji eksikliğinden önce, latent fazda uygulanması durumunda daha etkili olacağı hayvan deneylerinde gösterilmiştir (19). Ayrıca selektif baş soğutma tedavisinde hedef sıcaklığın $34.5 \pm 0.5^{\circ} \mathrm{C}$, total vucüt soğutma tedavisinde $33.5 \pm 0.5^{\circ} \mathrm{C}$ olması ve tedavinin 72 saat sürdürülmesi önerilmektedir (20-24). Hipoterminin süresi ve derinliği ile ilgili olarak yapılan çalışmalarda farklı veriler olmakla beraber Shankaran S. ve ark'larının (25) yaptığı çalışmada daha uzun süreli (120 saat) ve derin hipotermi uygulanması $\left(32^{\circ} \mathrm{C}\right)$ ile mortalitenin arttı̆̆ı, ancak yaşayan hastalarda 18-22 ay nörolojik ve Bayley III ile yapılan değerlendirmede daha düşük engellilik oranına sahip olduğu da belirtilmiştir. Çalışmamızda ise hastalara 72 saat boyunca $33.5 \pm 0.5^{\circ} \mathrm{C}$ sıcaklık hedeflenerek tedavi verilmiştir.

Çalışmada hipotermi uygulaması ve etkinliği gösterildikten sonra, hipotermi uygulanmayan grubunun alınamaması ya da hipotermi uygulanmayan grubun aynı yaş aralı̆ı̆ında olmaması nedeniyle kontrol grubu alınamamış olup, veriler literatür verileri kıyaslanmıştı. Ayrıca tek merkez olması ve hasta sayısının düşük olması da çalışmanın diğer kısıtlııklarıdır.

Sonuç olarak çalışmamızda da 18-36 ay döneminde gelişimsel gerilik oranı çalışmalar ile benzer şekilde saptanmıştır. Bu hastalarda erken dönem değerlendirmesinin normal olması durumunda bile minör sorunların belirlenmesi açısından özellikle okul dönemine kadar izlemlerine devam edilmesi önerilmektedir.

\section{KAYNAKLAR}

1. Levene MI, Sands C, Grindulis H, Moore JR. Comparison of two methods of predicting outcome in perinatal asphyxia. Lancet 1986;1:67-9.

2. Türk Neonatoloji Derneği Hipoksik İskemik Ensefalopati Çalışma Grubu. Türkiye'de yenidoğan yoğun bakım ünitelerinde izlenen hipoksik iskemik ensefalopatili olgular, risk faktörleri, insidans ve kısa dönem prognozları. Çocuk Sağlığı ve Hastalıkları Dergisi 2008;51:123-9.

3. Volpe JJ. Neonatal encephalopathy: an inadequate term for hypoxic-ischemic encephalopathy. Ann Neurol 2012;72:156-66.

4. Yuan J, Yankner BA. Apoptosis in the nervous system. Nature 2000;407:802-9.

5. Northington FJ, Graham EM, Martin LJ. Apoptosis in perinatalhypoxic-ischemic brain injury: how important is it and should itbe inhibited? Brain Res 2005;50:244-57.

6. Wassink G, Gunn ER, Drury PP, Bennet L, Gunn AJ. Themechanisms and treatment of asphyxial encephalopathy. Front Neurosci 2014;8:40.

7. Drury PP, Bennet L, Gunn AJ. Mechanisms of hypothermic neuroprotection. Semin Fetal Neonatal Med 2010;15:287-92.

8. Zhou WH, Cheng GQ, Shao XM, Liu XZ, Shan RB, Zhuang DY, et al. China Study Group Selective head cooling with mild systemic hypothermia after neonatal hypoxic-ischemic encephalopathy: a multicenter randomized controlled trial in China. J Pediatr 2010;157:367-72.

9. Simbruner G, Mittal RA, Rohlmann F, Muche R, neo.nEURO. network Trial Participants. Systemic hypothermia after neonatal encephalopathy: outcomes of neo.nEURO. network RCT. Pediatrics 2010;126:e771-8.

10. Jacobs SE, Morley CJ, Inder TE, Stewart MJ, Smith KR, McNamara PJ, et al. Infant Cooling Evaluation Collaboration Whole-body hypothermia for term and near-term newborns with hypoxicischemic encephalopathy: a randomized controlled trial. Arch Pediatr Adolesc Med 2011;165:692-700.

11. Shankaran S, Pappas A, McDonald SA, Vohr BR, Hintz SR, Yolton $\mathrm{K}$, et al. Eunice Kennedy Shriver $\mathrm{NI}$ Neonatal Research CHD Network Childhood outcomes after hypothermia for neonatal encephalopathy. N Engl J Med 2012;366:2085-92.

12. Azzopardi D, Strohm B, Marlow N, Brocklehurst P, Deierl A, Eddama $O$, et al. Effects of hypothermia for perinatal asphyxia on childhood outcomes. N Engl J Med 2014;371:140-9.

13. Kariholu U, Montaldo P, Markati T, Lally PJ, Pryce R, Teiserskas J, et al. Therapeutic hypothermia for mild neonatal encephalopathy: a systematic review and meta-analysis. Arch Dis Child Fetal Neonatal Ed 2020;105:225-8.

14. Prempunpong C, Chalak LF, Garfinkle J, Shah B, Kalra V, Rollins $\mathrm{N}$, et al. Prospective research on infants with mild encephalopathy: the PRIME study. J Perinatol 2018;38:80-5.

15. Bayley N. Bayley scales of infant development Manual. Psychological Corporation 1993:374.

16. Gunn AJ, Wyatt JS, Whitelaw A, Barks J, Azzopardi D, Ballard R, et al. Therapeutic hypothermia changes the prognostic value of clinical evaluation of neonatal encephalopathy. J Pediatr 2008;152:55-8. 
17. Guillet R, Edwards AD, Thoresen M, Ferriero DM, Gluckman PD, Whitelaw A, et al. Seven- to eight-year follow-up of the CoolCap trial of head cooling for neonatal encephalopathy. Pediatr Res 2012;71:205-9.

18. Finder M, Boylan GB, Twomey D, Ahearne C, Murray DM, Hallberg B. Two-Year Neurodevelopmental Outcomes After Mild Hypoxic Ischemic Encephalopathy in the Era of Therapeutic Hypothermia. JAMA Pediatr $2019 ; 174: 48-55$.

19. Drury PP, Gunn ER, Bennet L, Gunn AJ. Mechanisms of hypothermic neuroprotection. Clin Perinatol 2014;41:161-75.

20. Akula VP, Joe P, Thusu K, Davis AS, Tamaresis JS, Kim S, et al. A randomized clinical trial of therapeutic hypothermia mode during transport for neonatal encephalopathy. J Pediatr 2015;166:85661.

21. Edwards AD, Brocklehurst P, Gunn AJ, Halliday H, Juszczak E, Levene $M$, et al. Neurological outcomes at 18 months of ageafter moderate hypothermia for perinatal hypoxic ischaemic encephalopathy: synthesis and meta-analysis of trial data. BMJ 2010;340:c363.

22. Jacobs SE, Berg M, Hunt R, Tarnow-Mordi WO, Inder TE, Davis PG. Cooling for newborns with hypoxic ischaemic en- cephalopathy. Cochrane Database Syst Rev 2013;1:CD003311.

23. Kattwinkel J, Perlman JM, Aziz K, Colby C, Fairchild K, Gallagher J, et al. Part 15: Neonatal Resuscitation: 2010 American Heart Association Guidelines for Cardiopulmonary Resuscitation and Emergency Cardiovascular Care. Circulation 2010;122:S909-19.

24. Galinsky R, Dean JM, Lear CA, Davidson JO, Dhillon S, Wassink G, et al. In the Era of Therapeutic Hypothermia, How Well Do Studies of Perinatal Neuroprotection Control Temperature? Dev Neurosci 2017;39:7-22.

25. Shankaran S, Laptook AR, Pappas A, McDonald SA, Das A, Tyson JE, et al. Eunice Kennedy Shriver National Institute of Child Health and Human Development Neonatal Research Network. Effect of Depth and Duration of Cooling on Death or Disability at Age 18 Months Among Neonates With Hypoxic-Ischemic Encephalopathy: A Randomized Clinical Trial. JAMA 2017;318:57-67. 